\title{
HIV-1 Drug Resistance and Second-Line Treatment in Children Randomized to Switch at Low Versus Higher RNA Thresholds
}

\author{
Linda Harrison, MSc, * Ann Melvin, MD, $†$ Susan Fiscus, PhD, $\neq$ Yacine Saidi, PhD, $\S$ \\ Eleni Nastouli, MD, || Lynda Harper, MSc, $\mid$ Alexandra Compagnucci, MD, $\$$ Abdel Babiker, PhD, $\mid$ \\ Ross McKinney, MD,\# Diana Gibb, MD, MRCP, MSc, $\mid$ and Gareth Tudor-Williams, MD,** \\ and the PENPACT-1 (PENTA 9/PACTG 390) Study Team
}

\begin{abstract}
Background: The PENPACT-1 trial compared virologic thresholds to determine when to switch to second-line antiretroviral therapy (ART). Using PENPACT-1 data, we aimed to describe HIV-1 drug resistance accumulation on first-line ART by virologic threshold.
\end{abstract}

Methods: PENPACT-1 had a $2 \times 2$ factorial design, randomizing $\mathrm{HIV}$-infected children to start protease inhibitor (PI) versus nonnucleoside reverse transcriptase inhibitor (NNRTI)-based ART, and switch at a 1000 copies $/ \mathrm{mL}$ versus 30,000 copies $/ \mathrm{mL}$ threshold. Switch criteria were not achieving the threshold by week 24 , confirmed rebound above the threshold thereafter, or Center for Disease Control and Prevention stage $\mathrm{C}$ event. Resistance tests were performed on samples $\geq 1000$ copies/mL before switch, resuppression, and at 4-years/trial end.

Results: Sixty-seven children started PI-based ART and were randomized to switch at 1000 copies/mL (PI-1000), 64 PIs and 30,000 copies/mL (PI-30,000), 67 NNRTIs and 1000 copies $/ \mathrm{mL}$ (NNRTI-1000), and 65 NNRTI and 30,000 copies/mL (NNRTI$30,000)$. Ninety-four (36\%) children reached the 1000 copies $/ \mathrm{mL}$ switch criteria during 5-year follow-up. In 30,000 copies/mL threshold arms, median time from 1000 to 30,000 copies $/ \mathrm{mL}$ switch criteria was $58(\mathrm{PI})$ versus 80 (NNRTI) weeks $(P=0.81)$. In NNRTI-30,000, more nucleoside reverse transcriptase inhibitor (NRTI) resistance mutations accumulated than other groups. NNRTI mutations were selected before switching at 1000 copies/mL (23\% NNRTI-1000, 27\% NNRTI30,000). Sixty-two children started abacavir + lamivudine, 166 lamivudine + zidovudine or stavudine, and 35 other NRTIs. The abacavir + lamivudine group acquired fewest NRTI mutations. Of 60 switched to second-line, 79\% PI-1000, 63\% PI-30,000, 64\% NNRTI1000 , and $100 \%$ NNRTI-30,000 were $<400$ copies/mL 24 weeks later.

Conclusions: Children on first-line NNRTI-based ART who were randomized to switch at a higher virologic threshold developed the most resistance, yet resuppressed on second-line. An abacavir + lamivudine NRTI combination seemed protective against development of NRTI resistance.

Key Words: drug resistance, children, virologic switch criteria, second-line antiretroviral therapy

(J Acquir Immune Defic Syndr 2015;70:42-53)

Received for publication December 13, 2014; accepted March 4, 2015.

From the *Center for Biostatistics in AIDS Research, Harvard T.H. Chan School of Public Health, Boston, MA; †Seattle Children’s Hospital, Seattle, WA; $\ddagger$ School of Medicine, University of North Carolina at Chapel Hill, Chapel Hill, NC; §INSERM, SC10-US019, Paris, France; ||University College London Hospitals, University College London, London, United Kingdom; $\uparrow$ Medical Research Council Clinical Trials Unit, University College London, London, United Kingdom; \#Duke University Medical Center, Durham, NC; and **Imperial College London, London, United Kingdom.

The PENPACT-1 trial was sponsored jointly by the Paediatric European Network for Treatment of AIDS (PENTA) Foundation, Agence Nationale de Recherche sur le Sida et les hepatites virales (ANRS), and the Pediatric AIDS Clinical Trials Group (PACTG), subsequently the International Maternal Pediatric Adolescent AIDS Clinical Trials Group (IMPAACT). Overall support for PACTG/IMPAACT was provided by the National Institute of Allergy and Infectious Diseases (NIAID) of the National Institutes of Health (NIH) under Award Numbers UM1AI068632 (IMPAACT LOC), UM1AI068616 (IMPAACT SDMC), and UM1AI106716 (IMPAACT LC), with cofunding from the Eunice Kennedy Shriver National Institute of Child Health and Human Development (NICHD) and the National Institute of Mental Health (NIMH). The content is solely the responsibility of the authors and does not necessarily represent the official views of the NIH. PENTA is a coordinated action of the European Commission/European Union, supported by the 7th framework programme (FP7/2007-2013) under the Eurocoord grant agreement number 260694, the 6th framework contract number LSHP-CT-2006-018865, the 5th framework programme contract number QLK2-CT-2000-00150, and by the PENTA Foundation. UK clinical sites were supported by a grant from the MRC; those in Italy by a grant from the Istituto Superiore di Sanita-Progetto Terapia Antivirale 2004, 2005. GSK and BMS provided drugs in Romania. The trial was coordinated by 4 trials centers: the Medical Research Council (MRC) Clinical Trials Unit at University College London, London, United Kingdom (with support from the MRC); INSERM SC10-US019, Paris, France (supported by ANRS); Frontier Science, Buffalo, NY; and Westat, MD (supported by NICHD).

Presented at the Conference on Retroviruses and Opportunistic Infections (CROI), March 3-6, 2014, Boston, MA.

S.F. received an honorarium from Roche Molecular Systems for serving on a scientific advisory board. The remaining authors have no conflicts of interest to disclose.

Supplemental digital content is available for this article. Direct URL citations appear in the printed text and are provided in the HTML and PDF versions of this article on the journal's Web site (www.jaids.com).

Correspondence to: Linda Harrison, MSc, Center for Biostatistics in AIDS Research, Harvard T.H. Chan School of Public Health, 651 Huntington Avenue, Boston, MA 02115 (e-mail: lharriso@sdac.harvard.edu).

Copyright $(2015$ Wolters Kluwer Health, Inc. All rights reserved.

42 | www.jaids.com

J Acquir Immune Defic Syndr • Volume 70, Number 1, September 1, 2015 


\section{INTRODUCTION}

Pediatric guidelines ${ }^{1-3}$ recommend HIV-1-infected children initiate antiretroviral therapy (ART) early in life. Since ART dramatically reduces mortality, the duration of this treatment is likely to be long, potentially for many decades. Historically, children have tended to be maintained on failing therapies longer than adults, due to challenges with adherence and limited treatment options. This is particularly true in resource-limited settings where HIV-1 RNA monitoring is generally not available. HIV-1 drug resistance is known to increase with continuation of the same ART regimen in the presence of detectable viremia. Therefore, long-term treatment success requires effective first-line therapies, minimization of resistant virus on these therapies, and preservation of secondline options. Careful consideration is required when sequencing ART regimens, taking into account first-line ART exposure, acquisition of resistance mutations on first-line, and exposure to ART as part of programs to reduce mother to child transmission (MTCT).

The PENPACT- 1 trial $^{4}$ is the only long-term strategy trial in children or adults to assess effectiveness of first-line ART regimens and randomized RNA thresholds (1000 or 30,000 copies $/ \mathrm{mL}$ ) to determine when to switch to secondline. Over time, a 1000-copies $/ \mathrm{mL}$ threshold has been adopted to define virologic failure, followed by prompt switch to second-line in adults, but direct evidence for this threshold remains weak. When PENPACT-1 was designed in the early 2000 s, drug choice for children was limited, and switch to second-line could be delayed due to concerns that drug options would be quickly exhausted; therefore, a threshold $\sim 1.5 \log _{10}$ copies $/ \mathrm{mL}$ higher than 1000 copies $/ \mathrm{mL}$, above assay variation, was chosen to reflect practice at the time. In children, current recommendations for when to switch still vary, with the consolidated WHO guidelines ${ }^{1}$ recommending a switch time consistent with adults and the United States and European guidelines ${ }^{2,3}$ instead recommending assessment of reasons for virologic failure and consideration of drug availability, resistance profiles, adherence issues, and readiness of the family/child to switch.

Using data on all children from PENPACT-1, we explored resistance profiles after first-line ART by randomized switch-criteria based on RNA threshold, as well as second-line treatment response and drug options in children. The hypothesis was that more resistance mutations would accumulate on first-line ART in children randomized to the higher threshold, and this would influence second-line response and available second-line drug options.

\section{METHODS}

PENPACT-1 was a multicenter phase $2 / 3$, randomized, open-label, 2 by 2 factorial trial enrolling HIV-1-infected children from clinical centers in Europe and North and South America, with a minimum follow-up of 4 years. ${ }^{4}$ Children were naïve to ART, although infants who had received $<56$ days of ART to reduce MTCT were eligible. Children were simultaneously randomized to start ART with 2 nucleoside reverse transcriptase inhibitors (NRTIs) plus either a protease inhibitor (PI) or a nonnucleoside reverse transcriptase inhibitor (NNRTI) and to switch from first-line to second-line ART at an RNA threshold of 1000 copies $/ \mathrm{mL}$ (low threshold) or 30,000 copies $/ \mathrm{mL}$ (higher threshold). First-line ART was defined as the initial regimen, allowing drug substitutions (ideally within the same class) for nonvirologic reasons (eg, toxicity). The initial regimen was chosen by the treating clinician according to the randomized group. Children were switched to second-line if the RNA threshold $(<1000$ or $<30,000$ copies $/ \mathrm{mL})$ was not achieved by week 24 , or if after an initial decline in RNA by week 24, there was a confirmed RNA rebound at/above the randomized threshold. Switch to second-line was also required if the child experienced a new Center for Disease Control and Prevention stage $\mathrm{C}$ event at/after week 24. For analysis purposes, children were defined in both arms as reaching the " 1000 criteria" and " 30,000 criteria" using the above definition. Children who received first-line containing a PI were strongly encouraged to switch to a second-line containing an NNRTI and vice versa. Children had RNA measured at enrollment, weeks $8,16,24$, and then 12 weekly until the last enrolled child reached 4 years.

Baseline resistance tests were performed on samples collected within 84 days before randomization. During follow-up, the overall aim was to evaluate new HIV-1 drug resistance mutations accumulated on first-line. As children were randomized to early (low threshold) versus later (higher threshold) switch points, requirements for resistance testing aimed to identify additional mutations accumulated if a policy to switch at the " 30,000 criteria" compared with the " 1000 criteria" was applied. To capture this, resistance tests were required in both RNA threshold arms, while children were on $\mathrm{ART}$, at (1) the last sample with RNA $\geq 1000$ copies $/ \mathrm{mL}$ before switch, (2) the last sample after confirmed RNA $\geq 1000$ copies $/ \mathrm{mL}$ (eg, if not switched because " 30,000 criteria" not met and RNA resuppressed to $<1000$ copies $/ \mathrm{mL}$ ), and (3) samples with RNA $\geq 1000$ copies $/ \mathrm{mL}$ at 4 years or trial end. To further visualize the requirements for switch and resistance testing, we have provided a Supplemental Digital Content Figure (available at http://links.lww.com/QAI/A682) displaying a set of example RNA profiles. It can be seen that children in the higher-threshold arm would be tested later when we hypothesize more resistance mutations will have accumulated. It can also be noted, that some RNA profiles required multiple tests per child. Major resistance mutations were defined according to International AIDS Society-USA guidelines. ${ }^{5}$ New mutations on first-line were accumulated over postbaseline tests. ${ }^{6}$ Susceptibility to specific ART drugs was defined as fully susceptible, potential low-level, low-level, intermediate-, and high-level resistance by the genotypic resistance interpretation algorithm available on the Stanford University HIV drug resistance database Webpage. ${ }^{7}$ Genotypic sensitivity from this algorithm was formulated for current WHO recommended second-lines.

In this analysis, unlike the primary publication, ${ }^{4}$ 4 children who started a drug class (PI or NNRTI) different to their randomization were grouped based on the drug class actually started, rather than the strict intent-to-treat definition based on randomized class. Proportions of children reaching criteria were tested using $\chi^{2}$ tests, time to reach switch criteria and to actual switch used Kaplan-Meier 
methods and log-rank tests, and comparison of time to resistance tests and RNA levels used Wilcoxon rank-sum tests. Poisson regression, without a time offset, tested differences in number of mutations by group. The model assumed children not requiring resistance tests did not develop mutations and excluded those with missing test results. For second-line efficacy, a child was considered successful if they achieved $<400$ copies $/ \mathrm{mL} 24$ weeks after switch. Proportions of children $<400$ copies $/ \mathrm{mL}$ were calculated from Kaplan-Meier curves and comparisons used Cox regression. Analysis used Stata statistical software.

\section{RESULTS}

\section{Baseline Characteristics and First-Line ART}

Table 1 shows baseline age, HIV-1 RNA, resistance, HIV-1 subtype, previous ART use for reduction of MTCT, and first-line ART for the 263 children enrolled in PENPACT-1 initiating therapy and included in this analysis. Other baseline characteristics have previously been published. ${ }^{4}$ Median (range) age at start of ART was $6.5(0.1-$ $17.8)$ years. Thirty-nine children $(15 \%)$ received ART for reduction of MTCT; most zidovudine prophylaxis alone and only $5(2 \%)$ received single-dose nevirapine. Four percent (10/239) of baseline samples tested retrospectively had $\geq 1$ major mutation. Of children starting PI-based ART, 65 (50\%) started lopinavir/ritonavir and 64 (49\%) nelfinavir, whereas for children starting NNRTIs, 82 (62\%) started efavirenz and $50(38 \%)$ nevirapine. For NRTIs, $166(63 \%)$ initiated lamivudine + zidovudine or stavudine, $62(24 \%)$ abacavir + lamivudine, and 35 (13\%) other NRTI combinations (mainly lamivudine + didanosine).

\section{Children Reaching the 1000 and 30,000 copies/mL Switching Criteria}

By trial end, at a median follow-up of 5.0 years (interquartile range, 4.2-6.0), 94 children (36\%) had reached the "1000 criteria" (51 low threshold, 43 higher threshold, $\left.\chi^{2} P=0.42\right)$. These 94 children were evenly distributed by drug class; 51 (54\%) started PIs and 43 (46\%) NNRTIs $\left(\chi^{2} P=0.42\right)$. Median RNA when the "1000 criteria" were met was 13,505 copies/mL for those on PIs and 9800 copies/mL for NNRTIs (Wilcoxon ranksum $P=0.49$ ). As expected, most children in the lowthreshold arm switched soon after reaching the "1000 criteria" (median time to switch after reaching "1000 criteria": 12 weeks). This time was similar in children starting PIs (12 weeks) and NNRTIs ( 8 weeks, log-rank $P=$ 0.60) (Fig. 1, solid line). Of 43 children in the higherthreshold arm who reached the "1000 criteria", 3 (7\%) switched before subsequently reaching the "30,000 criteria," $22(55 \%)$ reached the " 30,000 criteria" before trial end (18 switched), and the remaining $18(42 \%)$ neither reached the "30,000 criteria" nor switched. The median time from reaching the " 1000 criteria" to the " 30,000 criteria" was 80 weeks (Fig. 1, dotted dashed line). This observed time was longer for those starting NNRTIs (median 80 weeks)

44 | www.jaids.com compared with PIs (median 58 weeks), although not significantly different (log-rank $P=0.81)$. However, there was an observed shorter time from reaching the " 1000 criteria" to switch for those on NNRTIs (25th percentile: 17 weeks) compared with PIs (25th percentile: 63 weeks, logrank $P=0.16$ ) (Fig. 1, solid dashed line). The median RNA when the "30,000 criteria" were met was 54,991 copies/mL (NNRTIs 44,550 copies/mL versus PIs 69,649 copies/mL, Wilcoxon rank-sum $P=0.09$ ).

\section{Resistance Tests Required and Performed}

In total, 107 children required resistance tests (Table 2). This included 90/94 children reaching the 1000 criteria and 17 additional children. The 4 children reaching the "1000 criteria" not requiring tests were due to 1 child switching at a Center for Disease Control and Prevention stage $C$ event with suppressed RNA and 3 being off ART for all RNAs $\geq 1000$ copies $/ \mathrm{mL}$. The 17 additional tests were due to single RNA $\geq 1000$ copies/mL at 4 years, trial end or before switch. These 107 children required 127 tests on firstline; $90(84 \%)$ required 1 test, $14(13 \%) 2$ tests, and $3(3 \%) 3$ tests. The reasons for requiring resistance tests were (1) last sample with RNA $\geq 1000$ copies/mL before switch $(\mathrm{n}=58)$, (2) last sample after confirmed RNA $\geq 1000$ copies/mL (eg, if not switched because "30,000 criteria" not met and RNA resuppressed to $<1000$ copies/mL) $(\mathrm{n}=24)$, and (3) samples with RNA $\geq 1000$ copies $/ \mathrm{mL}$ at 4 years or trial end $(n=45)$ (see Figure, Supplemental Digital Content, http://links.lww. com/QAI/A682 for example RNA profiles and resistance testing requirements). Overall, 101/127 (80\%) tests were available for $87 / 107(81 \%)$ children. The 20 children with missing test results were similarly distributed across first-line regimen and randomized switch thresholds ( $\chi^{2}$ on 3 degrees of freedom $P=0.76)$. For 87 children with available resistance tests on first-line, median time from randomization to last resistance test was 72 weeks in the low-threshold and 124 weeks in the higher-threshold arm (Wilcoxon ranksum $P=0.009)$. For PIs, this was 50 versus 121 weeks $(P=$ $0.01)$ and for NNRTIs, 95 versus 148 weeks $(P=0.35)$.

\section{HIV-1 Resistance Mutations Accumulated on First-Line ART}

Table 2 displays new major International AIDS Society-USA resistance mutations accumulated on firstline. More NRTI mutations accumulated in NNRTI-higher than the other 3 groups, with more children selecting $\geq 3$ mutations in NNRTI-higher driving this difference (Poisson $P<0.001)$. Overall, more NNRTI than PI mutations accumulated (Poisson $P<0.001$ ). It seemed that NNRTI mutations had already been selected before switching at the "1000 criteria" as NNRTI-low had a similar number of mutations to NNRTI-higher. PI mutations were developed by $16 \%$ in PI-low and 7\% in PI-higher; note more nelfinavir was administered in PI-low. For nonrandomized NRTIs, 5 $(9 \%)$ on abacavir + lamivudine, $39(25 \%)$ on lamivudine + zidovudine or stavudine, and $6(21 \%)$ on other NRTI combinations developed mutations (Poisson $P<0.01$ ). 
TABLE 1. Baseline Age, HIV-1 RNA, IAS Resistance Mutations, HIV-1 Subtype, ART for Reduction of MTCT and First-Line ART by Randomized Switch Threshold

\begin{tabular}{|c|c|c|c|}
\hline & \multicolumn{2}{|c|}{ Randomized Switch Threshold } & \multirow[b]{2}{*}{ Total $(n=263)$} \\
\hline & Low $(n=134)$ & Higher $(n=129)$ & \\
\hline Age (yrs), median (IQR) [range] & $6.1(2.5-13.1)[0.3-17.8]$ & $6.9(3.1-12.5)[0.1-17.5]$ & $6.5(2.8-12.9)[0.1-17.8]$ \\
\hline HIV-1 RNA (copies/mL), median (IQR) & $99,646(35,488-446,704)$ & $119,356(28,732-434,369)$ & $107,813(31,251-446,704)$ \\
\hline Baseline resistance test available* & $121(100 \%)$ & $118(100 \%)$ & $239(100 \%)$ \\
\hline Any major mutations & $7(6 \%)$ & $3(3 \%)$ & $10(4 \%)$ \\
\hline 1 or 2 mutations & 7 & 2 & 9 \\
\hline NNRTI V108I & 1 & 0 & 1 \\
\hline NNRTI Y181C & 2 & 1 & 3 \\
\hline NNRTI Y188L & 1 & 0 & 1 \\
\hline PI Q58E & 1 & 0 & 1 \\
\hline NNRTI K101P Y181C & 1 & 0 & 1 \\
\hline NRTI D67N K219Q, NNRTI K103N & 0 & 1 & 1 \\
\hline $\mathrm{C}$ & $13(10 \%)$ & $12(10 \%)$ & $25(10 \%)$ \\
\hline $\mathrm{F}$ & $25(20 \%)$ & $23(19 \%)$ & $48(19 \%)$ \\
\hline $\mathrm{A} / \mathrm{CRF} \_\mathrm{AG} / \mathrm{D} / \mathrm{G}$ & $25(20 \%)$ & $27(22 \%)$ & $52(21 \%)$ \\
\hline Unclassified & $13(10 \%)$ & $10(8 \%)$ & $23(9 \%)$ \\
\hline ART use before randomization for reduction of MTCT $t$ & $22(100 \%)$ & $17(100 \%)$ & $39(100 \%)$ \\
\hline In utero (to the mother) & $4(18 \%)$ & $6(35 \%)$ & $10(26 \%)$ \\
\hline $1 \mathrm{~d} Z \mathrm{ZDV}+\mathrm{NVP}$ & 0 & 1 & 1 \\
\hline $1-24$ wks ZDV + 3TC + NVP & 2 & 2 & 4 \\
\hline $1-2$ wks $\mathrm{ZDV}+3 \mathrm{TC}+\mathrm{NFV}$ & 1 & 1 & 2 \\
\hline $7-28$ wks ZDV & 1 & 2 & 3 \\
\hline Delivery/postpartum (to the infant) & $22(100 \%)$ & $16(94 \%)$ & $38(97 \%)$ \\
\hline Single-dose NVP, $1-4$ wks ZDV +3 TC & 0 & 2 & 2 \\
\hline $\mathrm{d} 4 \mathrm{~T}+3 \mathrm{TC}$ & 6 & 3 & 9 \\
\hline Other NRTIs§ & 5 & 8 & 13 \\
\hline NVP with & $24(36 \%)$ & $26(40 \%)$ & $50(38 \%)$ \\
\hline $\mathrm{ABC}+3 \mathrm{TC}$ & 3 & 6 & 9 \\
\hline $\mathrm{ZDV}+3 \mathrm{TC}$ & 15 & 11 & 26 \\
\hline $\mathrm{d} 4 \mathrm{~T}+3 \mathrm{TC}$ & 3 & 8 & 11 \\
\hline Other NRTIs $\|$ & 3 & 1 & 4 \\
\hline First-line PI ART & $67(100 \%)$ & $64(100 \%)$ & $131(100 \%)$ \\
\hline LPV/r with & $29(43 \%)$ & $36(56 \%)$ & $65(50 \%)$ \\
\hline $\mathrm{ABC}+3 \mathrm{TC}$ & 10 & 12 & 22 \\
\hline $\mathrm{ZDV}+3 \mathrm{TC}$ & 10 & 20 & 30 \\
\hline $\mathrm{d} 4 \mathrm{~T}+3 \mathrm{TC}$ & 6 & 4 & 10 \\
\hline Other NRTIs & 3 & 0 & 3 \\
\hline NFV with & $37(55 \%)$ & $27(42 \%)$ & $64(49 \%)$ \\
\hline $\mathrm{ABC}+3 \mathrm{TC}$ & 3 & 3 & 6 \\
\hline $\mathrm{ZDV}+3 \mathrm{TC}$ & 12 & 9 & 21 \\
\hline $\mathrm{d} 4 \mathrm{~T}+3 \mathrm{TC}$ & 13 & 10 & 23 \\
\hline
\end{tabular}


TABLE 1. (Continued) Baseline Age, HIV-1 RNA, IAS Resistance Mutations, HIV-1 Subtype, ART for Reduction of MTCT and FirstLine ART by Randomized Switch Threshold

\begin{tabular}{cccc}
\hline & \multicolumn{2}{c}{ Randomized Switch Threshold } & Higher $(\mathbf{n}=\mathbf{1 2 9})$ \\
\cline { 2 - 3 } Total $(\mathbf{n}=\mathbf{2 6 3})$ & Low $(\mathbf{n}=\mathbf{1 3 4})$ & 5 & 14 \\
Other NRTIs\# & 9 & $1(2 \%)$ & $2(2 \%)$ \\
Other PI & $1(1 \%)$ & 1 & 1 \\
ZDV + 3TC + high-dose ritonavir & 0 & 0 & 1 \\
ddI + 3TC + fosamprenavir/ritonavir & 1 & 1 \\
\hline
\end{tabular}

Children are displayed in 2 groups defined by their randomized switch threshold (low $=1000 \mathrm{copies} / \mathrm{mL}$, higher $=30,000 \mathrm{copies} / \mathrm{mL}$ )

*Includes 1 test where only the protease gene was sequenced.

$\dagger$ Available from 239 baseline resistance tests and 10 resistance tests during follow-up.

$\$$ For $3 / 5$ children who received single-dose NVP, the mother also received NVP in utero.

$\$ 10 \mathrm{ZDV}+$ ddI, $23 \mathrm{TC}+\mathrm{ddI}, 1 \mathrm{ddI}+\mathrm{FTC}$.

$\| 1 \mathrm{ZDV}+\mathrm{ddI}, 1 \mathrm{ZDV}+\mathrm{ABC}, 2 \mathrm{ddI}+\mathrm{d} 4 \mathrm{~T}$.

-1 ZDV + ddI, $2 \mathrm{ZDV}+\mathrm{ABC}$

\#13 ZDV + ddI, $1 \mathrm{ddI}+\mathrm{d} 4 \mathrm{~T}$.

3TC, lamivudine; ABC, abacavir; d4T, stavudine; ddI, didanosine; EFV, efavirenz; FTC, emtricitabine; IAS, International AIDS Society-USA; IQR, interquartile range; LPV/r, lopinavir/ritonavir; MTCT, mother-to-child transmission; NFV, nelfinavir; NRTI, nucleoside reverse transcriptase inhibitor; NVP, nevirapine; ZDV, zidovudine.

Figure 2 provides a detailed description of first-line ART administered and mutations accumulated. It reveals, in PI-low and PI-higher, very few PI mutations were selected by children on lopinavir/ritonavir and relatively more on nelfinavir. On lopinavir/ritonavir, the main NRTI mutation selected was M184V, but on nelfinavir, additional NRTI mutations were accumulated. All 5 children who developed NRTI mutations on abacavir + lamivudine were on NNRTIs, whereas 22/39 $(56 \%)$ children on lamivudine + zidovudine or stavudine with mutations were on NNRTIs and 17/39 (44\%) on PIs.

\section{Susceptibility to Potential Second-Line ART}

Figure 3 displays susceptibility to potential second-line regimens. All children on first-line abacavir + lamivudine with lopinavir/ritonavir were fully susceptible to WHO recommended second-line lamivudine + zidovudine with efavirenz in PI-low and PI-higher. Eleven (73\%) in PI-low and $20(87 \%)$ in PI-higher were fully susceptible to WHO recommended second-line after first-line lamivudine + zidovudine or stavudine with lopinavir/ritonavir. After first-line abacavir + lamivudine with an NNRTI, 14 (82\%) in NNRTIlow and $12(80 \%)$ in NNRTI-higher were fully susceptible to second-line lamivudine + zidovudine with lopinavir/ritonavir. After first-line lamivudine + zidovudine or stavudine with an NNRTI, $32(80 \%)$ in NNRTI-low and $26(65 \%)$ in NNRTIhigher were fully susceptible to second-line lamivudine + abacavir or tenofovir with lopinavir/ritonavir. This likely reflects accumulation of thymidine analog mutations (TAMs) on zidovudine or stavudine.

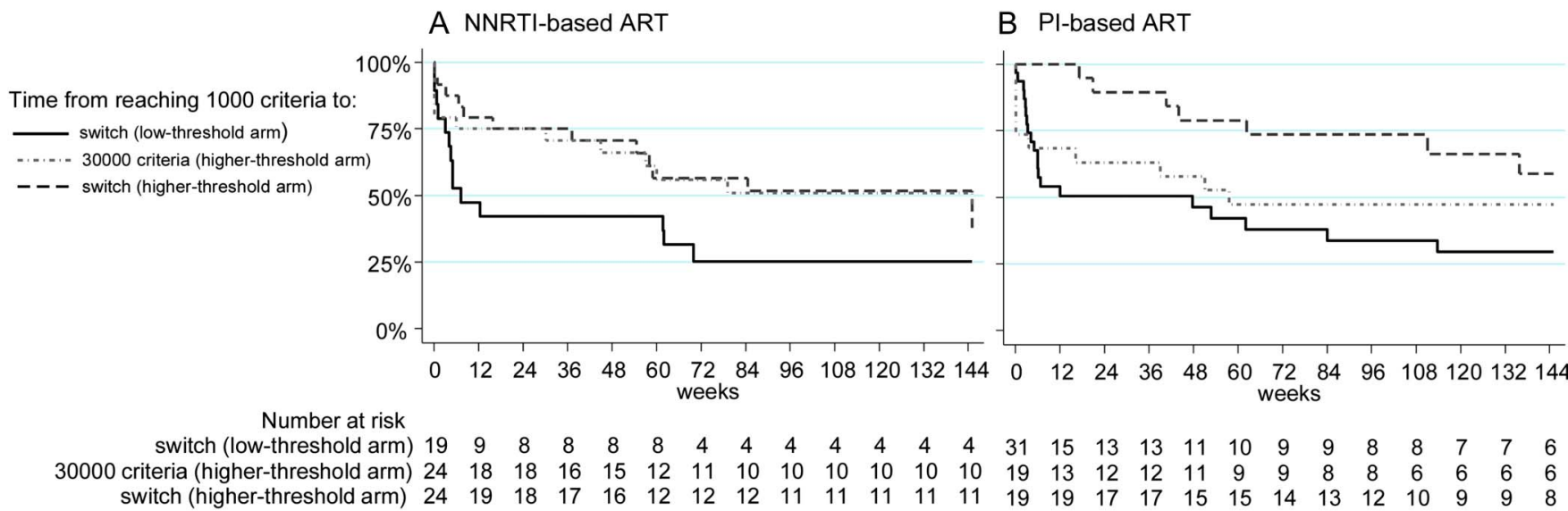

FIGURE 1. Kaplan-Meier curves displaying the time from reaching the 1000 criteria to switch in the low-threshold arm (solid line), time from the 1000 criteria to the 30,000 criteria in the higher-threshold arm (dotted dashed line), and time from the 1000 criteria to switch in the higher-threshold arm (solid dashed line) by first-line NNRTI-based (A) or PI-based ART (B). The 1000 criteria were defined as not achieving HIV-1 RNA $<1000$ copies/mL by week 24 , confirmed rebound $\geq 1000$ copies/mL thereafter or Center for Disease Control and Prevention (CDC) stage C event. The 30,000 criteria were defined as not achieving HIV-1 RNA $<30,000$ copies/mL by week 24 , confirmed rebound $\geq 30,000$ copies/mL thereafter or CDC stage C event. Children in the lowthreshold arm were randomized to switch at the 1000 criteria, and those in the higher-threshold arm to switch at the 30,000 criteria. Ninety-four children reached the 1000 criteria during the trial, but 93 children are displayed in the figure as 1 child on PIbased first-line ART randomized to switch at the low-threshold ended follow-up on the same day as reaching the 1000 criteria. 
TABLE 2. Major IAS Resistance Mutations Accumulated on First-Line ART

\begin{tabular}{|c|c|c|c|c|c|}
\hline & PI-Low & PI-Higher & NNRTI-Low & NNRTI-Higher & Poisson $P^{*}$ \\
\hline Total children & 67 & 64 & 67 & 65 & \\
\hline Number requiring tests $\dagger$ & 34 & 22 & 26 & 25 & \\
\hline Number with test results & 28 & 17 & 20 & 22 & \\
\hline \multicolumn{6}{|l|}{ NRTI resistance, $\%$} \\
\hline 1 or 2 mutations & $11(18)$ & $7(12)$ & $12(20)$ & $12(19)$ & any difference \\
\hline$\geq 3$ mutations & $0(0)$ & $1(2)$ & $0(0)$ & $7(11)$ & $<0.001$ \\
\hline 1 or 2 mutations & $10(16)$ & $4(7)$ & $13(21)$ & $12(19)$ & PI versus NNRTI \\
\hline \multirow[t]{2}{*}{$\geq 3$ mutations } & $0(0)$ & $0(0)$ & $1(2)$ & $5(8)$ & $<0.001$ \\
\hline & $\mathrm{ABC}+3 \mathrm{TC}$ & \multicolumn{2}{|c|}{$3 T C+\mathrm{ZDV} / \mathrm{d} 4 \mathrm{~T}$} & Other (Mainly ZDV + ddI) & Poisson $P^{*}$ \\
\hline Total children & 62 & \multicolumn{2}{|c|}{166} & 35 & \\
\hline Number requiring tests $\dagger$ & 15 & \multicolumn{2}{|c|}{67} & 25 & \\
\hline$\geq 3$ mutations & $1(2)$ & \multicolumn{2}{|c|}{$7(4)$} & $0(0)$ & $<0.01$ \\
\hline \multicolumn{6}{|l|}{ TAMs, $\%$} \\
\hline 1 or 2 TAMs & $0(0)$ & \multicolumn{2}{|c|}{$6(4)$} & $6(21)$ & \\
\hline$\geq 3$ TAMs & $0(0)$ & \multicolumn{2}{|c|}{$4(3)$} & $0(0)$ & \\
\hline K65R & $1(2)$ & \multicolumn{2}{|c|}{$0(0)$} & $0(0)$ & \\
\hline L74R & $1(2)$ & \multicolumn{2}{|c|}{$1(1)$} & $0(0)$ & \\
\hline $\mathrm{Y} 115 \mathrm{~F}$ & $1(2)$ & \multicolumn{2}{|c|}{$0(0)$} & $0(0)$ & \\
\hline M184V/I & $5(9)$ & \multicolumn{2}{|c|}{$39(25)$} & $0(0)$ & \\
\hline
\end{tabular}

Children are displayed in 4 groups defined by the class of ART initiated as first-line (PI-based versus NNRTI-based) and their randomized switch threshold (low $=1000$ copies/mL, higher $=30,000$ copies $/ \mathrm{mL}$ ).

*Analysis assumes those not requiring tests were not resistant and excludes those with unavailable resistance results.

$\dagger$ Resistance tests were required on first-line, while children were on ART, at (1) the last sample with RNA $\geq 1000$ copies/mL before switch, (2) the last sample after confirmed RNA $\geq 1000$ copies $/ \mathrm{mL}$ (eg, if not switched because 30,000 criteria not met and RNA resuppressed to $<1000 \mathrm{copies} / \mathrm{mL}$ ), and (3) samples with RNA $\geq 1000$ copies $/ \mathrm{mL}$ at 4 years or trial end. IAS major resistance mutations were accumulated across multiple tests per child on first-line, where appropriate. The table displays number of children requiring tests and the number of children with test results, rather than the absolute number of tests performed.

3TC, lamivudine; ABC, abacavir; d4T, stavudine; ddI, didanosine; IAS, International AIDS Society-USA; NRTI, nucleoside reverse transcriptase inhibitor; ZDV, zidovudine.

\section{Second-Line Response}

Sixty children switched to second-line during PENPACT-1 (20 PI-low, 8 PI-higher, 17 NNRTI-low, 15 NNRTI-higher). Five switched before reaching the "1000 criteria" (3 low threshold, 2 higher threshold) and 55 (34 low threshold, 21 higher threshold) after they were met; 18 of the 21 in the higher-threshold arm waited until the "30,000 criteria" were met, but 3 did not. The proportion $<400$ copies $/ \mathrm{mL}$ by 24 weeks on second-line was $79 \%$ in PI-low, 63\% PI-higher, 64\% NNRTI-low, and $100 \%$ NNRTI-higher (Cox regression $P=0.10$ ). Of $46 / 60$ children with resistance data on first-line, 18 (39\%) had no NRTI mutations, 22 (48\%) 1-2 NRTI mutations, and 6 $(13 \%) \geq 3$ NRTI mutations (all 6 were in NNRTI-higher). Of those without NRTI resistance, 93\% suppressed to $<400$ copies/mL by 24 weeks on second-line, whereas for those with 1-2 NRTI mutations, $65 \%$ suppressed, and those with $\geq 3$ NRTI mutations, $100 \%$ suppressed (Cox regression $P=0.64)$. The Supplemental Digital Content list (http://links.lww.com/QAI/A682) provides a detailed description of these children.

\section{DISCUSSION}

Throughout the world, children continue to initiate both NNRTI- and PI-based first-line regimens in national treatment programs. Our long-term trial including a wide age range of children starting first-line PIs and NNRTIs provided a unique opportunity to study development of HIV-1 drug resistance and gain insight into resistance consequences of different ART switching strategies. Overall and as predicted, we found that children starting NNRTIs accumulated more HIV-1 drug resistance than those starting PIs. In particular, children switching later on NNRTIs accumulated more NRTI mutations, whereas on PIs, NRTI mutations did not accumulate over the time taken to reach a 30,000 copies $/ \mathrm{mL}$ threshold. Children taking the currently recommended lopinavir/ritonavir selected even fewer mutations than those on the unboosted PI, nelfinavir, which is no longer recommended. Furthermore, in this study, before tenofovir was available in children (now approved by the FDA for children $>2$ years), there was a resistance benefit for children prescribed first-line abacavir + lamivudine compared with lamivudine + zidovudine or stavudine, but randomized evidence to verify this finding is required. 


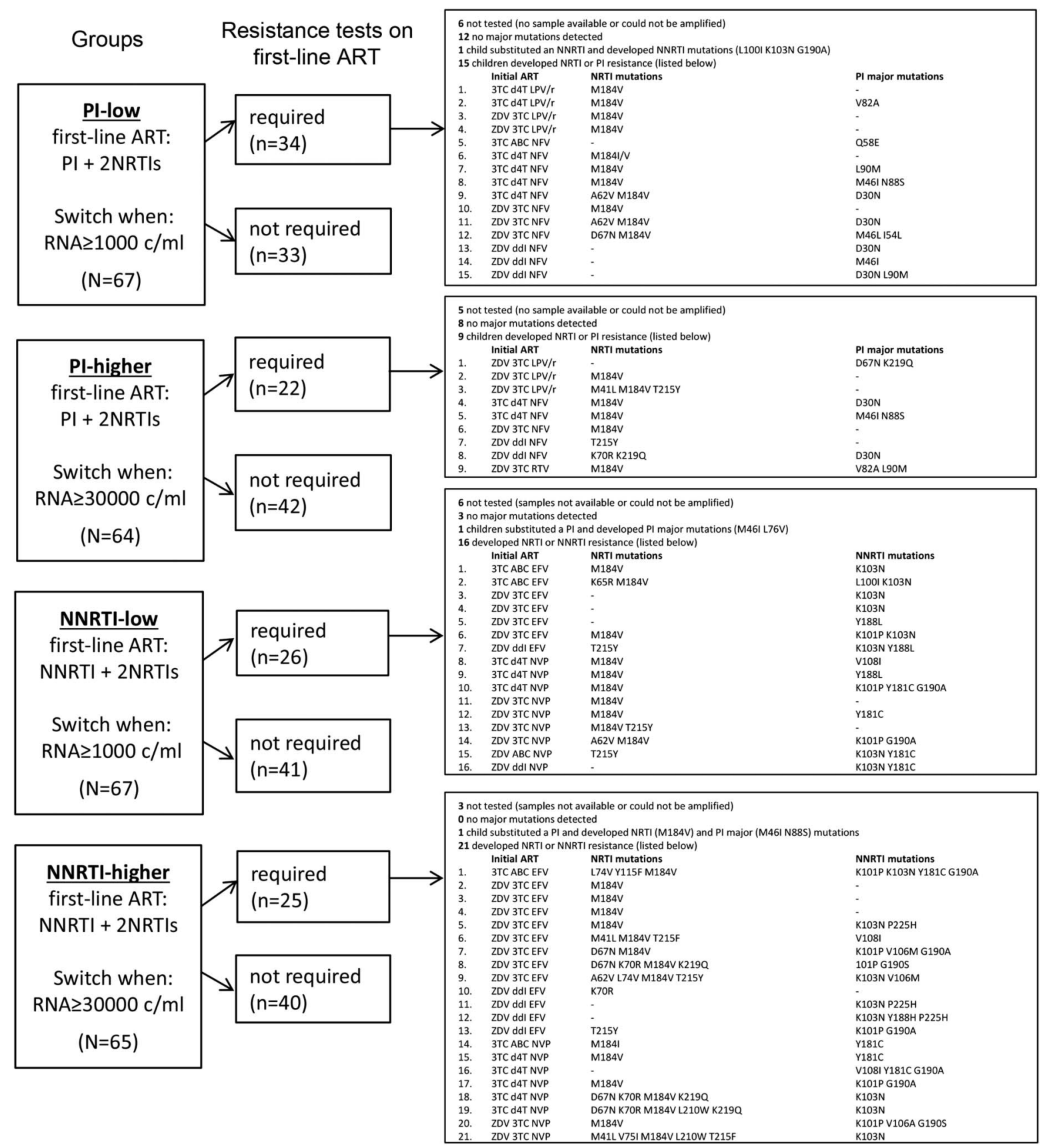

FIGURE 2. Major IAS resistance mutations accumulated on first-line ART. Children are displayed in 4 groups defined by the class of ART initiated as first-line (PI based versus NNRTI based) and their randomized switch threshold (low $=1000 \mathrm{copies} / \mathrm{mL}$ versus higher $=30,000$ copies $/ \mathrm{mL}$ ). Resistance tests were required on first-line in both randomized switch threshold arms, while children were on ART, at (1) the last sample with RNA $\geq 1000$ copies/mL before switch, (2) the last sample after confirmed RNA $\geq 1000$ copies $/ \mathrm{mL}$ (eg, if not switched because 30,000 criteria not met and RNA resuppressed to $<1000 \mathrm{copies} / \mathrm{mL}$ ), and (3) samples with RNA $\geq 1000$ copies/mL at 4 years or trial end. 3TC, lamivudine; ABC, abacavir; d4T, stavudine; ddl, didanosine; EFV, efavirenz; IAS, International AIDS Society-USA; LPV/r, lopinavir/ritonavir; NFV, nelfinavir; NRTI, nucleoside reverse transcriptase inhibitor; NVP, nevirapine; RTV, high-dose ritonavir; ZDV, zidovudine.

Over approximately 5 years on ART, suppression on first-line regimens was good with only around one-third of children ever reaching the " 1000 criteria" for switch. Of those, the observed time from 1000 to " 30,000 criteria" was

48 | www.jaids.com slightly longer for NNRTIs compared with PIs, but time from "1000 criteria" to switch was longer for PIs than NNRTIs. This suggests children failing on NNRTIs spent a slightly longer time with RNA between 1000 and

Copyright (C) 2015 Wolters Kluwer Health, Inc. All rights reserved. 


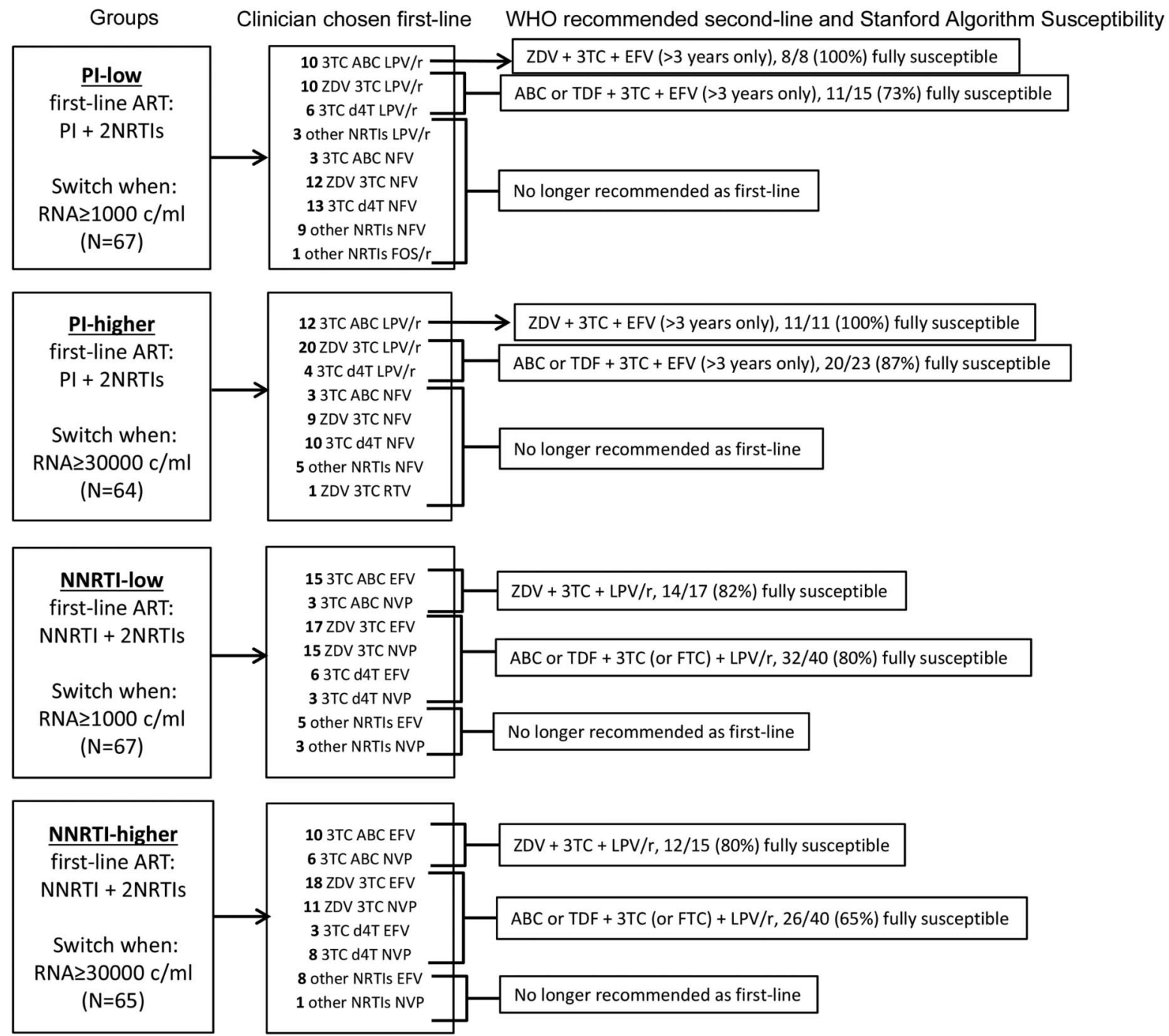

FIGURE 3. Second-line ART options. Children are displayed in 4 groups defined by the class of ART initiated as first-line (PI based versus NNRTI based) and their randomized switch threshold (low $=1000$ copies $/ \mathrm{mL}$ versus higher $=30,000 \mathrm{copies} / \mathrm{mL}$ ). The clinician chosen initial first-line ART is displayed along with current WHO recommended second-line and the susceptibility to this potential second-line regimen by the Stanford algorithm. The proportion of children susceptible to the potential second-line options assumed that children not meeting requirements for resistance testing were susceptible and excludes children with unavailable resistance results. Second-line containing EFV is only recommended for children $>3$ years and has been noted on the figure. 3TC, lamivudine; ABC, abacavir; d4T, stavudine; ddl, didanosine; EFV, efavirenz; FOS/r, fosamprenavir/ritonavir; FTC, emtricitabine; LPV/r, lopinavir/ritonavir; NFV, nelfinavir; NRTI, nucleoside reverse transcriptase inhibitor; NVP, nevirapine; RTV, high-dose ritonavir; TDF, tenofovir; ZDV, zidovudine.

30,000 copies/mL with prompt switch once the " 30,000 criteria" were met. In contrast, children on PIs spent a slightly shorter time with RNA between 1000 and 30,000 copies $/ \mathrm{mL}$, but the treating clinician had a tendency to wait to switch after the " 30,000 criteria" were met, possibly due to assessment of adequate adherence before switching to an NNRTI-based second-line. Despite this tendency to wait to switch on PIs, which hypothetically would result in more resistance mutations, we still saw less resistance accumulate in PI-higher compared with NNRTIhigher. These data are consistent with clinical trials and observational studies in adults, reporting fewer NRTI mutations on PIs than NNRTIs, ${ }^{8,9}$ as well as additional reports on accumulation of NRTI resistance on NNRTIs. ${ }^{10-12}$

As well as the overall protective effect of PIs, we saw fewer NRTI and PI resistance mutations for children on the boosted PI lopinavir/ritonavir compared with other PIs (mainly unboosted nelfinavir). This is consistent with a systematic review of drug resistance after first-line failure in children, ${ }^{13}$ which observed that the type of PI affected development of resistance. In particular, on nelfinavir, where adequate plasma concentrations are seldom reached in children, ${ }^{14}$ D30N and N88S, specific nelfinavir mutations, were frequently reported. The review did not describe NRTI 
mutations by PI exposure, but our data suggest PI choice is likely to be important as lopinavir/ritonavir seemed particularly protective against accumulation of NRTI mutations. This is supported by CHER trial data ${ }^{15}$ where only $11 / 331(3 \%)$ children initiating lopinavir/ritonavir based first-line developed NRTI mutations, 10 of which developed M184V alone and no TAMs were seen.

To our knowledge, PENPACT-1 is the only trial of randomized criteria for switching from first- to second-line ART based on RNA thresholds. There has been 1 small short-term trial where highly ART experienced adults were randomized to immediate or deferred switch, ${ }^{16}$ and 2 trials comparing monitoring strategies with resistance data by arm. ${ }^{17,18}$ In the small ART experienced trial, ${ }^{16}$ median time to meeting criteria was $>60$ weeks suggesting a similar delayed switch time to our study. A trend toward more new mutations in the deferred-switch compared with the immediate-switch arm was observed, with most new mutations to NRTIs, particularly TAMs. However, particular drugs or drug classes could not be assessed. The first monitoring trial ${ }^{17}$ compared CD4 with RNA monitoring and revealed no difference in a future drug options score between arms. However, more patients in the CD4 arm, which had a longer duration $>400$ copies $/ \mathrm{mL}$, had $\geq 3 \mathrm{NRTI}$ mutations. The only 2 patients who developed TAMs were in the CD4 arm. These data are consistent with our study, showing a low barrier to development of lamivudine and NNRTI resistance, which is similar in the 2 arms, but documentation of TAM accumulation in the arm with longer duration of virologic failure. The other monitoring trial, ${ }^{18}$ compared laboratory and clinical monitoring to clinical monitoring alone, and showed a similar number of patients with major mutations in the clinical monitoring alone versus the laboratory and clinical monitoring arm. The authors noted that switching occurred late after first detectable RNA in the laboratory and clinical monitoring arm, which may account for the fact no differences were seen.

Since the advent of triple therapy, 2 randomized trials ${ }^{19,20}$ on NRTI backbones in children suggest abacavir + lamivudine has similar or better efficacy compared with other NRTI combinations. Our data add to the current weight of evidence that prescribing an NRTI backbone of abacavir + lamivudine first-line followed by zidovudine in second-line has some resistance advantages, as previously described in the PENTA-5 trial. ${ }^{21}$ For children prescribed abacavir + lamivudine in combination with lopinavir/ritonavir, we did not detect any resistance, and in combination with NNRTIs, we only saw 5 children with NRTI resistance. The abacavir-specific mutations do not affect susceptibility to second-line zidovudine, and there is evidence that K65R induces hypersusceptibility to zidovudine. ${ }^{22}$ Conversely, using zidovudine (or stavudine) first-line results in accumulation of TAMs such that the efficacy of abacavir second-line is reduced. Overall accumulation of NRTI resistance on lamivudine + zidovudine or stavudine was greater than on abacavir + lamivudine with TAMs occurring in 10 children (including 1 on lopinavir/ ritonavir), suggesting abacavir + lamivudine has beneficial resistance properties when prescribed first-line with lopinavir/ ritonavir or NNRTIs. More than 2 TAMs accumulated for
4 children on lamivudine + zidovudine or stavudine and 5 children developed mutations from the TAM type 1 pathway, which is known to have a negative impact on response to abacavir. $^{22}$ In addition, the M184V mutation, present in nearly all children developing resistance on first-line, increases susceptibility to thymidine analogs (zidovudine and stavudine) but causes low-level resistance to abacavir. ${ }^{22}$ Therefore, these data support a resistance benefit of prescribing abacavir + lamivudine first-line in settings where children may spend longer with high RNAs due to limited laboratory monitoring or unavailable second-line regimens.

Our data on efficacy of second-line are limited by the small number of children switching by trial end. However, the data suggest a similar (or maybe better) suppression rate after failing in the NNRTI-higher arm. The effect of NRTI resistance before switch on second-line efficacy revealed a consistent pattern, suggesting children who had developed 1-2 NRTI mutations on first-line did worst and those with $\geq 3$ mutations best. In our data, there was no evidence that clinicians selected more potent second-line regimens for children known to be failing with extensive resistance, so one could hypothesize that a boosted PI with partially effective NRTIs is sufficiently potent to suppress virus at least until week 24 of second-line. Alternatively, it may be that adherence more than drug resistance influences second-line success; 2 studies in adults ${ }^{23,24}$ with resistance tests before switch from an NNRTI- to PI-based ART found either no association of NRTI resistance with the success of second-line or paradoxically a higher suppression rate in those with resistance. The authors of the second study found evidence from pharmacokinetic drug levels that it was indeed adherence rather than drug resistance that influenced second-line success.

\section{CONCLUSIONS}

This study confirms the protective effect of a boosted PI against accumulation of HIV-1 drug resistance mutations, as reported in adult studies. Analysis of nonrandomized NRTI backbones suggests that abacavir + lamivudine results in fewer resistance mutations than lamivudine + zidovudine or stavudine, whether prescribed with an NNRTI or lopinavir/ ritonavir. Overall, these data support WHO 2013 pediatric guidelines ${ }^{1}$ recommending abacavir + lamivudine as the firstline NRTI backbone with an NNRTI and provide reassurance that despite the possibility of considerable time spent on firstline with detectable viremia (where HIV-1 RNA monitoring is not available), response to second-line with a boosted PI and zidovudine + lamivudine is expected to be good.

\section{ACKNOWLEDGMENTS}

The authors thank all the children, families, and staff from the centers participating in the PENPACT-1 (PENTA 9/PACTG 390) trial.

\section{REFERENCES}

1. World Health Organisation. Consolidated Guidelines on the Use of Antiretroviral Drugs for Treating and Preventing HIV Infection; Recommendations for a Public Health Approach. 2013. Available at: http://www.who.int/hiv/pub/guidelines/arv2013/en/. Accessed December $13,2014$.

Copyright (C) 2015 Wolters Kluwer Health, Inc. All rights reserved. 
2. Panel on Antiretroviral Therapy and Medical Management of HIV-Infected Children. Guidelines for the Use of Antiretroviral Agents in Pediatric HIV Infection. Available at: http://aidsinfo.nih.gov/ guidelines. Accessed December 13, 2014.

3. PENTA Steering Committee. PENTA 2009 guidelines for the use of antiretroviral therapy in paediatric HIV-1 infection. HIV Med. 2009;10: 591-613.

4. PENPACT-1 (PENTA 9/PACTG 390) Study Team. First-line antiretroviral therapy with a protease inhibitor versus non-nucleoside reverse transcriptase inhibitor and switch at higher versus low viral load in HIV-infected children: an open-label, randomised phase 2/3 trial. Lancet Infect Dis. 2011;11:273-283.

5. Johnson VA, Brun-Vezinet F, Clotet B, et al. Update of the drug resistance mutations in HIV-1: December 2009. Top HIV Med. 2009;17: 138-145.

6. Pillay D, Green H, Matthias R, et al. Estimating HIV-1 drug resistance in antiretroviral-treated individuals in the United Kingdom. J Infect Dis. 2005;192:967-973.

7. Stanford University HIV Drug Resistance Database. Available at: http:/ hivdb/stanford.edu/. Accessed December 13, 2014.

8. Hill A, McBride A, Sawyer AW, et al. Resistance at virological failure using boosted protease inhibitor versus nonnucleoside reverse transcriptase inhibitors as first-line antiretroviral therapy-implications for sustained efficacy of ART in resource-limited settings. J Infect Dis. 2013;207(suppl 2):S78-S84.

9. Scherrer AU, Boni J, Yerly S, et al. Long-lasting protection of activity of nucleoside reverse transcriptase inhibitors and protease inhibitors (PIs) by boosted PI containing regimens. PLoS One. 2012;7:e50307.

10. Cozzi-Lepri A, Phillips A, Ruiz L, et al. Evolution of drug resistance in HIV-infected patients remaining on a virologically failing combination antiretroviral therapy regimen. AIDS. 2007;21:721-732.

11. Barth RE, Aikten SC, Tempelman H, et al. Accumulation of drug resistance and loss if therapeutic options precede commonly used criteria for treatment failure in HIV-1 subtype-C-infected patients. Antivir Ther. 2012;17:377-386.

12. Sigaloff KCE, Ramatsebe T, Viana R, et al. Accumulation of HIV drug resistance mutations in patients failing first-line antiretroviral treatment in South Africa. AIDS Res Hum Retroviruses. 2012;28: 171-175.

13. Sigaloff KCE, Calis JCJ, Geelen SP, et al. HIV-1-resistance-associated mutations after failure of first-line antiretroviral treatment among children in resource-poor regions: a systematic review. Lancet Infect Dis. 2011; 11:769-779.

14. Bergshoeff AS, Fraaij PL, van Rossum AM, et al. Pharmacokinetics of nelfinavir in children: influencing factors and dose implications. Antivir Ther. 2003;8:215-222.

15. Violari A, Cotton M, Otwombe K, et al. Does early initiation of ART in infants affect virological and resistance outcomes? Data from the CHER trial after 6 years of follow-up. J Int AIDS Soc. 2012;15 (suppl 4): 18085

16. Riddler SA, Jiang H, Tenorio A, et al. A randomized study of antiviral medication switch at lower- versus higher-switch threshold: AIDS Clinical Trials Group Study A5115. Antivir Ther. 2007;12: $531-541$

17. Jourdain G, Le Coeur S, Ngo-Giang-Huong N, et al. Switching HIV treatment in adults based on CD4 count versus viral load monitoring: a randomized, non-inferiority trial in Thailand. PLoS Med. 2013;10: e1001494.

18. Laurent C, Kouanfack C, Laborde-Balen G, et al. Monitoring of HIV viral loads, CD4 cell counts, and clinical assessment versus clinical monitoring alone for antiretroviral therapy in rural district hospitals in Cameroon (Stratal ANRS 12110/ESTHER): a randomized noninferiority trial. Lancet Infect Dis. 2011;11:825-833.

19. Paediatric European Network for Treatment of AIDS (PENTA). Comparison of dual nucleoside-analogue reverse-transcriptase inhibitor regimens with and without nelfinavir in children with HIV-1 who have not previously been treated: the PENTA 5 randomised trial. Lancet. 2002;359:733-740.

20. Musiime V, Kekitiinwa A, Mulenga A, et al. CHAPAS 3: a randomized trial comparing stavudine vs zidovudine vs abacavir as NRTI backbone in NNRTI-based first-line ART in 478 HIV-infected children in Uganda and Zambia. Rev Antivir Ther Infect Dis. 2014;6; Abstract O_21:22.
21. Gibb DM, Walker AS, Kaye S, et al. Evolution of antiretrovira phenotypic and genotypic drug resistance in antiretroviral-naïve HIV-1infected children treated with abacavir/lamivudine, zidovudine/lamivudine or abacavir/zidovudine, with or without nelfinavir (the PENTA 5 trial). Antivir Ther. 2002;7:293-303.

22. Stanford University HIV Drug Resistance Database, NRTI Resistance Notes. Available at: http://hivdb.stanford.edu/DR/NRTIResiNote.html. Accessed December 13, 2014.

23. Waters L, Bansi L, Asboe D, et al. Second-line protease inhibitor-based antiretroviral therapy after non-nucleoside reverse transcriptase inhibitor failure: the effect of nucleoside backbone. Antrivir Ther. 2013;18:213-219.

24. Johnston V, Cohen K, Wiesner L, et al. Viral suppression following switch to second-line antiretroviral therapy: associations with nucleoside reverse transcriptase inhibitor resistance and subtherapeutic drug concentrations prior to switch. $J$ Infect Dis. 2014;209:711-720.

\section{APPENDIX 1}

\section{PENPACT-1 Protocol Team: PACTG/ IMPAACT/NICHD}

P. Brouwers, D. Costello, E. Ferguson, S. Fiscus, J. Hodge, M. Hughes, C. Jennings, A. Melvin (Co-Chair), R. McKinney (Co-Chair), L. Mofenson, M. Warshaw, E. Smith, S. Spector, E. Stiehm, M. Toye, and R. Yogev.

\section{PENTA}

J. P. Aboulker, A. Babiker, H. Castro, A. Compagnucci, C. Giaquinto, J. Darbyshire, M. Debré, D. M. Gibb, L. Harper, L. Harrison, G. TudorWilliams (Co-Chair), Y. Saidi, and A. S. Walker.

\section{DSMB}

B. Brody, C. Hill, P. Lepage, J. Modlin, A. Poziak, M. Rein (Chair 2002-2003), M. Robb (Chair 2004-2009), T. Fleming, S. Vella, and K. M. Kim.

\section{Clinical Sites $(\mathrm{L}=$ laboratory, $\mathrm{P}=$ pharmacy): Argentina}

Hospital de Pediatria: Dr. J. P. Garrahan; Buenos Aires: R. Bologna, D. Mecikovsky, N. Pineda, L. Sen (L), A. Mangano (L), S. Marino (L), and C. Galvez (L); Laboratorio Fundai: G. Deluchi (L).

\section{Austria}

Universitätsklinik für Kinder und Jugendheilkunde, Graz: B. Zöhrer, W. Zenz, E. Daghofer, K. Pfurtscheller, and B. Pabst (L).

\section{Bahamas}

Princess Margaret Hospital: M. P. Gomez, P. McNeil, M. Jervis, I. Whyms, D. Kwolfe, and S. Scott (P).

\section{Brazil}

University of Sao Paulo at Ribeirao Preto: M. M. Mussi-Pinhata, M. L. Issac, M. C. Cervi, B. V. M. Negrini, T. C. Matsubara, C. B. S. S. de Souza (L), and J. C. Gabaldi (P); Institute of Pediatrics (IPPMG), Federal University of Rio de Janeiro: R. H. Oliveira, M. C. Sapia, T. Abreu, L. Evangelista, A. Pala, I. Fernandes, I. Farias, M. de F Melo (L), H. Carreira (P), and L. M. Lira (P); Instituto de Infectologia Emilio Ribas, Sao Paolo: M. della Negra, W. Queiroz, and Y. C. Lian; D. P. Pacola; Fleury Laboratories; Federal University of Minas Gerais, Belo Horizonte: J. Pinto, F. Ferreira, F. Kakehasi, L. Martins, A. Diniz, V. Lobato, M. Diniz, C. Hill (L) S. Cleto (L), S. Costa (P), and J. Romeiro (P).

\section{France}

Hôpital d'enfants Armand Trousseau, Paris: C. Dollfus, M. D Tabone, M. F. Courcoux, G. Vaudre, A. Dehée (L), A. Schnuriger (L), N. Le Gueyades (P), and C. De Bortoli (P); CHU Hôtel Dieu, Nantes: F. Méchinaud, V. Reliquet, J. Arias (L), A. Rodallec (L), E. André (L), I. Falconi (P), and A. Le Pelletier (P); Hôpital de l'Archet II, Nice: 
F. Monpoux, J. Cottalorda (L), and S. Mellul (L); Hôpital Jean Verdier, Bondy: E. Lachassinne; Laboratoire de virologie-Hôpital Necker Enfants Malades, Paris: J. Galimand (L), C. Rouzioux (L), M. L. Chaix (L), Z. Benabadji (P), and M. Pourrat (P); Hôpital Cochin Port-Royal-Saint Vincent de Paul, Paris: G. Firtion, D. Rivaux, M. Denon, N. Boudjoudi, F. Nganzali, A. Krivine (L), J. F. Méritet (L), G. Delommois (L), C. Norgeux (L), and C. Guérin (P); Hôpital Louis Mourier, Colombes: C. Floch, L. Marty, H. Hichou (L), and V. Tournier (P); Hôpital Robert Debré, Paris: A. Faye, I. Le Moal, M. Sellier (P), and L. Dehache (P); Laboratoire de virologieHôpital Bichat Claude Bernard, Paris: F. Damond (L), J. Leleu (L), D. Beniken (L), and G. Alexandre-Castor (L).

\section{Germany}

Universitäts—Kinderklinik Düsseldorf: J. Neubert, T. Niehues, H. J. Laws, K. Huck, S. Gudowius, (H. Loeffler), S. Bellert (L), and A. Ortwin (L); Universitäts-Kinderkliniken, Munich: G. Notheis, U. Wintergerst, and F. Hoffman, (A. Werthmann, S. Seyboldt, L. Schneider, B. Bucholz); Charité-Medizische Fakultät der Humboldt-Universität zu Berlin: C. Feiterna-Sperling, C. Peiser, R. Nickel, T. Schmitz, T. Piening, and C. Müller (L); Kinder-und Jugendklinik, Universität Rostock: G. Warncke, M. Wigger, and R. Neubauer.

\section{Ireland}

Our Lady's Hospital for Sick Children, Dublin: K. Butler, A. L. Chang, T. Belger, A. Menon, M. O'Connell, L. Barrett, A. Rochford, M. Goode, E. Hayes, S. McDonagy, A. Walsh, A. Doyle, J. Fanning (P), M. O'Connor (P), M. Byrne (L), N. O'Sullivan (L), and E. Hyland (L).

\section{Italy}

Clinica Pediatrica, Ospedale L. Sacco, Milan: V. Giacomet, A. Viganò, G. V. Zuccotti, D. Trabattoni (L), and A. Berzi (L); Clinica Pediatrica, Università di Brescia: R. Badolato, F. Schumacher, V. Bennato, M. Brusati, A. Sorlini, E. Spinelli, M. Filisetti, and C. Bertulli; Clinica Pediatrica, Università di Padova: O. Rampon, C. Giaquinto, and M. Zanchetta (L); Ospedale S. Chiara, Trento: A. Mazza, G. Stringari, and G. Rossetti (L); Ospedale del Bambino Gesù, Rome: S. Bernardi, A. Martino, G. Castelli Gattinara, P. Palma, G. Pontrelli, H. Tchidjou, A. Furcas, C. Frillici, A. Mazzei, A. Zoccano (P), and C. Concato (L).

\section{Romania}

Spitalul Clinic de Boli Infectioase Victor Babes, Bucharest: D. Duiculescu, C. Oprea, G. Tardei (L), and F. Abaab (P); Institutul de Boli Infectioase Matei Bals, Bucharest: M. Mardarescu, R. Draghicenoiu, D. Otelea (L), and L. Alecsandru (P); Clinic Municipal, Constanta: R. Matusa, S. Rugina, M. Ilie, and S. Netescu (P). Clinical monitors: C. Florea, E. Voicu, D. Poalelungi, C. Belmega, L. Vladau, and A. Chiriac.

\section{Spain}

Hospital Materno-Infantil 12 de Octubre, Madrid: J. T. Ramos Amador, M. I. Gonzalez Tomé, P. Rojo Conejo, M. Fernandez, R. Delgado Garcia (L), and J. M. Ferrari (P); Institute de Salud Carlos III, Madrid: M. Garcia Lopez, M. J. Mellado Peña, P. Martin Fontelos, and I. Jimenez Nacher (P); Biobanco Gregorio Marañon, Madrid: M. A. Muñoz Fernandez (L), J. L. Jimenez (L), and A. García Torre (L); clinical monitors: M. Penin, R. Pineiro Perez, and I. Garcia Mellado.

\section{United Kingdom}

Bristol Royal Children's Hospital: A. Finn, M. LaJeunesse, E. Hutchison, J. Usher (L), L. Ball (P), and M. Dunn (P); St. George's Healthcare NHS Trust, London: M. Sharland, K. Doerholt, S. Storey, S. Donaghy, C. Wells (P), K. Buckberry (P), and P. Rice (P); University Hospital of North Staffordshire: P. McMaster, P. Butler, C. Farmer (L), J. Shenton (P), H. Haley (P), and J. Orendi (L); University Hospital Lewisham: J. Stroobant, L. Navarante, P. Archer, C. Mazhude, D. Scott, R. O'Connell, J. Wong (L), and G. Boddy (P); Sheffield Children's Hospital: F. Shackley, R. Lakshman, J. Hobbs, G. Ball (L), G. Kudesia (L), J. Bane (P), and D. Painter (P); Ealing Hospital NHS Trust: K. Sloper, V. Shah,
A. Cheng (P), and A. Aali (L); King's College Hospital, London: C. Ball, S. Hawkins, D. Nayagam, A. Waters, and S. Doshi (P); Newham University Hospital: S. Liebeschuetz, B. Sodiende, D. Shingadia, S. Wong, J. Swan $(\mathrm{P})$, and Z. Shah (P); Royal Devon and Exeter Hospital: A. Collinson, C. Hayes, J. King (L), and K. O'Connor (L); Imperial College Healthcare NHS Trust, London: G. Tudor-Williams, H. Lyall, K. Fidler, S. Walters, C. Foster, D. Hadamache, C. Newbould, C. Monrose, S. Campbell, S. Yeung, J. Cohen, N. Martinez-Allier, (G. Tatum, A. Gordon), S. Kaye (L), D. Muir (L), and D. Patel (P); Great Ormond Street Hospital: V. Novelli, D. Gibb, D. Shingadia, K. Moshal, J. Lambert, N. Klein, J. Flynn, L. Farrelly, M. Clapson, L. Spencer, and M. Depala (P); Institute of Child Health, London: M. Jacobsen (L); John Radcliffe Hospital, Oxford: S. Segal, A. Pollard, S. Yeadon, Y. Peng (L), T. Dong (L), Y. Peng (L), K. Jeffries (L), and M. Snelling (P); Nottingham University Hospitals: A. Smyth and J. Smith; Chelsea and Westminster Hospital, London: B. Ward; UCLH, London: E. Jungmann; Doncaster Royal Infirmary: C. Ryan and K. Swaby; Health Protection Agency, London: A. Buckton (L); Health Protection Agency, Birmingham: E. Smidt (L).

\section{United States}

Harlem Hospital Center: E. J. Abrams, S. Champion, A. D. Fernandez, D. Calo, L. Garrovillo, K. Swaminathan, T. Alford, and M. Frere; Columbia University laboratories: J. Navarra (P. Town Total Health); NYU School of Medicine: W. Borkowsky, S. Deygoo, T. Hastings, S. Akleh, and T. Ilmet (L); Seattle Children's Hospital: A. Melvin, K. Mohan, and G. Bowen; University of South Florida: P. J. Emmanuel, J. Lujan-Zimmerman, C. Rodriguez, S. Johnson, A. Marion, C. Graisbery, D. Casey, and G. Lewis; All Children's Hospital laboratories; Oregon Health and Science University: J. Guzman-Cottrill and R. Croteau; San Juan City Hospital: M. Acevedo-Flores, M. Gonzalez, and L. Angeli; L. Fabregas, Lab 053, P. Valentin (P); SUNY-Upstate Medical UniversitySyracuse: L. Weiner, K. A. Contello, W. Holz, and M. Butler; SUNY, Health Science Center at Stonybrook: S. Nachman, M. A. Kelly, and D. M. Ferraro, Howard University Hospital: S. Rana, C. Reed, E. Yeagley, A. Malheiro, and J. Roa; LAC and USC Medical Center: M. Neely, A. Kovacs, L. Spencer, J. Homans, and Y. Rodriguez Lozano; Maternal Child Virology Research Laboratory, Investigational Drug Service; South Florida Childrens Diagnostic \& Treatment Center: A. Puga, G. Talero, and R. Sellers; Broward General Medical Center, University of Miami (L); University College of Florida College of Medicine-Gainesville: R. Lawrence; University of Rochester Pediatrics: G. A. Weinberg, B. Murante, and S. Laverty; Miller Children's Hospital Long Beach: A. Deveikis, J. Batra, T. Chen, D. Michalik, J. Deville, K. Elkins, S. Marks, J. Jackson Alvarez, J. Palm, I. Fineanganofo (L), M. Keuth (L), L. Deveikis (L), and W. Tomosada (P); Tulane University New Orleans: R. Van Dyke, T. Alchediak, M. Silio, C. Borne, S. Bradford, S. Eloby-Childress (L), and K. Nguyen (P); University of Florida/Jacksonville: M. H. Rathore, A. Alvarez, A. Mirza, S. Mahmoudi, and M. Burke; University of Puerto Rico: I. L. Febo, L. Lugo, and R. Santos; Children's Hospital Los Angeles: J. A. Church, T. Dunaway, and C. Rodier; St. Jude/UTHSC: P. Flynn, N. Patel, S. DiScenza, and M. Donohoe; WNE Maternal Pediatric Adolescent AIDS: K. Luzuriaga and D. Picard; Texas Children's Hospital: M. Kline, M. E. Paul, W. T. Shearer, and C. McMullenJackson; Children's Memorial Hospital, Chicago: R. Yogev, E. Chadwick, E. Cagwin, and K. Kabat; New Jersey Medical School: A. Dieudonne, P. Palumbo, and J. Johnson; Robert Wood Johnson Medical School, New Brunswick: S. Gaur and L. Cerracchio; Columbia IMPAACT: M. Foca, A. Jurgrau, S. Vasquez Bonilla, and G. Silva; Babies' Hospital, Columbia/Presbyterian Medical Center, NY (A. Gershon); University of Massachusetts Medical Center, Worcester (J. Sullivan); UCLA Medical Center, Los Angeles (Y. Bryson); Children's Hospital, Seattle: L. Frenkel; UNCChapel Hill Virology Lab: S. Fiscus (L) and J. Nelson (L).

\section{Trials Units/Support \\ INSERM SC10-US019 Paris, France}

J. P. Aboulker, A. Compagnucci, G. Hadjou, S. Léonardo, Y. Riault, and Y. Saïdi. 


\section{MRC Clinical Trials Unit at University College London, United Kingdom}

A. Babiker, L. Buck, J. H. Darbyshire, L. Farrelly, S. Forcat, D. M. Gibb, H. Castro, L. Harper, L. Harrison, J. Horton, D. Johnson, C. Taylor, and A. S. Walker.

\section{Westat/NICHD, United States}

D. Collins, S. Buskirk, P. Kamara, C. Nesel, M. Johnson, and A Ferreira.

\section{Frontier Science, Buffalo, NY, United States}

J. Hodge, J. Tutko, and H. Sprenger.

\section{IMPAACT SDAC, Harvard T.H. Chan School of Public Health, Boston, MA, United States}

M. Hughes, M. Warshaw, P. Britto, C. Powell, and L. Harrison.

\section{NIAID, Bethesda, MD, United States}

R. DerSimonian and E. Handelsman.

\section{PENTA Steering Committee}

J. P. Aboulker, J. Ananworanich, A. Babiker, E. Belfrage, S. Bernardi, S. Blanche, A. B. Bohlin, R. Bologna, D. Burger, K. Butler, G. Castelli-Gattinara, H. Castro, P. Clayden, A. Compagnucci, T. Cressey, J. H. Darbyshire, M. Debré, R. De Groot, M. Della Negra, A. De Rossi, D. Duicelescu (deceased), A. Faye, V. Giacomet, C. Giaquinto (Chair), D. M. Gibb, I. Grosch-Wörner, M. Hainault, N. Klein, M. Lallemant, J. Levy, H. Lyall, M. Marczynska, L. Marques, M. Mardarescu, M. J. Mellado Pena, D. Nadal, E. Nastouli, L. Naver, T. Niehues, A. Noquera, C. Peckham, D. Pillay, J. Popieska, J. T. Ramos Amador, P. Rojo Conejo, L. Rosado, R. Rosso (deceased), C. Rudin, Y. Saïdi, H. Scherpbier, M. Sharland, M. Stevanovic, C. Thorne, P. A. Tovo, G. Tudor-Williams, A. Turkova, N. Valerius, A. Volokha, A. S. Walker, S. Welch, and U. Wintergerst. 